Saudi Journal of Medicine

Abbreviated Key Title: Saudi J Med ISSN 2518-3389 (Print) |ISSN 2518-3397 (Online)

\title{
Observational Study on the Use of Streptokinase in Patients with Acute Myocardial Infarction and its Outcome at Discharge
}

\author{
Mohamed Shameem ${ }^{1}$, Sivakumar $\mathrm{R}^{2 *}$, Komala $\mathrm{M}^{3}$, Bargavi B. $\mathrm{H}^{3}$ \\ ${ }^{1}$ The Erode College of Pharmacy, Perundurai main Road, Veppampalayam, Vallipurathampalayam (Po), Erode, Tamil Nadu 638112, \\ India \\ ${ }^{2}$ Professor, Grace College of Pharmacy, Athalur, Melamuri Kottayi Road, Kodunthirapully, Palakkad, Kerala 678004, India \\ ${ }^{3}$ Vels Institute of Science Technology and Advanced Studies, PV Vaithiyalingam Rd, Velan Nagar, Krishnapuram, Pallavaram, \\ Chennai, Tamil Nadu 600117, India
}

DOI: $10.36348 /$ sjm.2021.v06i04.002

| Received: 16.03.2021 | Accepted: 21.04.2021 | Published: 30.04.2021

*Corresponding Author: Sivakumar R

\section{Abstract}

Acute myocardial infarction is the leading cause of death. Streptokinase is the most commonly used thrombolytic agent. This study was conducted to compare in-hospital outcome of patients with acute myocardial infarction receiving streptokinase with those not receiving it. About 340 patients having acute MI were included in the study. Two groups were formed. Group 1 (SK Group) receiving streptokinase and Group 2(Non SK) not receiving streptokinase. For the patient condition assessment In-hospital mortality was the primary end while mechanical and electrical complications were the secondary end points. Among 340 patients, 255(75\%) were males and 85(25\%) females. Out of those 218 received streptokinase, while 122 did not receive the drug The mean age of group 1 was $53.1 \pm 10.3$ years and group 2 age was $60.5 \pm 16$ years. Mean time of arrival to the hospital after symptom onset was $10.4 \pm 9.97 \mathrm{~h}$. SK group patients reached in $5.9 \pm 4.7$ hours while group 2 in $19.4 \pm 10.5 \mathrm{~h}$. In-hospital mortality in group 1 and group 2 was $19(8.7 \%)$ and $25(20.5 \%)$ respectively, $(p=0.002)$. Complication rate was significantly higher in non-streptokinase group. Patients of acute myocardial infarction receiving streptokinase have significantly lesser in hospital mortality and complications as compared to patients not receiving it.

Keywords: Acute Myocardial Infarction, Streptokinase, In - Hospital Mortality.

Copyright $\odot 2021$ The Author(s): This is an open-access article distributed under the terms of the Creative Commons Attribution 4.0 International License (CC BY-NC 4.0) which permits unrestricted use, distribution, and reproduction in any medium for non-commercial use provided the original author and source are credited.

\section{INTRODUCTION}

Myocardial infarction (heart attack) is the irreversible necrosis of heart muscle secondary to prolonged ischemia. Acute myocardial infarction (MI) remains a leading cause of morbidity and mortality worldwide, millions of people die each year [1]. The benefits of early thrombolysis are well established and proved to reduce mortality and morbidity [2]. For this reason there is much current interest in the use of thrombolysis in the management of acute myocardial infarction.

Increasing rates of coronary heart disease (CHD) and death from acute myocardial infarction (AMI) necessitating increase in use of thrombolytic and primary percutaneous coronary interventions (PCI). So treating CHD has become a strategic priority for the World Health Organization (WHO). Thrombolytic treatment prevents approximately 20-30 death per 1000 patients treated, with a proportional reduction of mortality up to $25 \%$ in certain group [3]. Myocardial infarction is associated with thrombotic occlusion of coronary arteries in high proportion of patients during onset of symptoms. Studies shows that reperfusion is possible with thrombolytic agents thus infarct size will limited [4]. Thrombolysis is preferred for all patients with AMI presenting within 6 hours of onset of symptoms [5].

Streptokinase is the agent of choice for patients presenting with inferior MI [6]. These patients are lower risk because the site of infarct does not have the same effect on the left ventricle as, for example, an anterior MI. There is a tenfold increase in the cost of Alteplase compared to streptokinase and anecdotally this has played a significant part in the use of streptokinase. Adverse effects of thrombolysis are Hypotension, Allergy, Bleeding, Stroke [7, 8]. 
The purpose of the study was to observe the physical condition of the patients who have receiving intravenous streptokinase for acute myocardial infarction.

\section{METHODOLOGY Study Site}

The study was conducted in Coronary Care Unit, Saba hospital, Payyannur. Kannur, Kerala. It is a 150 bedded specialty hospital with Reg: No 442/90. A Unit of North Malabar Development Society. Which include technically skilled medical and non-medical staffs.

\section{Study Design}

Prospective Observational study, main outcome measure was the post thrombolytic complications and physical condition at discharge. Demographic data and relevant medical history was obtained from all patients prior to thrombolysis therapy. Post thrombolytic complications and physical conditions of patients at discharge were collected.

\section{Study Duration}

It was a 6 month study; it was carried out from 1 December 2011 to June 2012.

\section{Study Subjects}

Total 50 patients admitted in CCU Saba hospital during period of Dec 2011 to 1 June 2012 who had suffered Myocardial Infarction. Patients with recent on-set AMI without contraindication to thrombolytic therapy are involved. Diagnosis is made through ECG. The National Institutes of Health Consensus Development Conference in 1980 listed criteria for selecting patients who could safely be treated with thrombolytic therapy. Within that restriction we prepared inclusion and exclusion criteria

A total of 50 patients who met the inclusion criteria were enrolled in the study. Diagnosis of AMI has been confirmed by ECG reports.

Inclusion Criteria: Patient presenting to $\mathrm{CCU}$ within 5 $\mathrm{h}$ of the onset of Acute Myocardial Infarction. ECG criteria in Myocardial Infarction must be satisfied.

Exclusion Criteria: The Drug ccontraindication to thrombolytis, Pregnant women's, Re-infarction and primary angioplasty patients are excluded for the study.

\section{Data Collection}

Design of data collection form: Suitable data collection form was designed to collect and document the data. Data collection form includes the provision for collection of information related to Demographic details, Social status, other data; it includes presence of Diabetes mellitus, Hypertension, Ischemic heart disease, Dyslipidemia, Stroke, Kidney disease. Also adjuvant therapy involved like use of Beta blocker, use of ACE inhibitor, use of LMWH.ECG findings, complication at presentation, diagnosis, thrombolysis with, post thrombolysis complication if any, condition at discharge are also collected. All the collected data will document in designed data collection form.

\section{Study Procedure}

During the study period it was hospital policy to admit all patients with Myocardial infarction to Coronary Care Unit. Patients admitted in CCU of hospital will undergo thrombolysis using streptokinase. Those patients who met study criteria were enrolled in to study. Records of patients receiving thrombolytic agent using streptokinase in $\mathrm{CCU}$ were reviewed on daily basis.

All the necessary data including Age, Gender, Body weight, DOA, DOD, beside this social habits, presence of DM, HT, IHD, Dyslipidemia, Stroke, Kidney disease, ECG findings, other adjuvant therapy prescribed, complication at presentation, diagnosis, thrombolysis with, post thrombolysis complication if any and condition at discharge etc. are collected and documented in data form. Information was collected from In Patients visiting along with physician daily.

\section{Statistical Analysis}

The data was collected and analyzed. Then data was analyzed using Chi square test for trend, Fisher's exact test and K S normality test using Graph pad prism 6.00 trial software. Using this Mean, Median, Standard deviation (SD) and 'p' values are calculated. Values $<0.05$ consider as significant value,

\section{RESULTS AND DISCUSSION}

All the study results are tabulated in Table 1-5. In the present study, The streptokinase standard universal dose was $\left(1.5 \times 10^{6} \mathrm{IU}\right.$ for 60 minutes $)$. A total of 50 patients were included. Out of them, 27(54\%) were males and $23(46 \%)$ were females. ' $p$ ' value found significant. In this study maximum number of patients 29 of AMI is found in the age group (50-60) of this less number of patients 06 was found in the age group above 70. ' $\mathrm{p}$ ' value non-significant. In this study the average days per AMI patient's with thrombolytic was stayed in hospital was 5-6 days per patients. 'p' value nonsignificant. Among the enrolled 50 patients had comorbid conditions along with AMI. Most commonly reported co-morbidity was hypertension 41(82\%) patients followed by Dyslipidemia 33 patients $(66 \%)$, diabetes mellitus 23 patients $(46 \%)$. ' $\mathrm{p}$ ' value found significant. In this study enrolled AMI patients social habits shows that, no of patient having smoking habits are $23(26 \%)$, alcoholic patients are $10(20 \%)$. 'p' value found significant. Details are given in Table 5. In this study social habits in both female and male AMI patients were compared. ' $p$ ' value found significant, details listed in the Table 6. In this study enrolled patients showing co-morbidities at presentation shows $30(60 \%)$ patients suffered of no co-morbidities. ECG 
Mohamed Shameem et al.; Saudi J Med, Apr, 2021; 6(4): 65-69

findings in MI patients.In this study ECG criteria used to diagnose MI shows that $26(52 \%)$ patients reported IWMI, and $23(46 \%)$ patients with AWMI. 'p' value found significant. In our study ECG criteria were used to identify the site of infarction is compared in males and females. 'p' value found non-significant. The study showed that maximum use of streptokinase was recorded in age group of 60-70 (58\%). Less use is recorded in age group above $70(12 \%)$. ('p' value nonsignificant). Main adjunctive therapy used to treat MI patients were ASA, LMWH in 50 patients, 47 patients respectively. Beta Blocker and ACE inhibitors were also used in 37 patients. ('p' value significant). Use of different combination for treating AMI is including $\beta$ blocker + LMWH + ASA+ACE inhibitors is used in 26 patients $(52 \%), \beta$ blockers + LMWH+ ASA is used in 9 patients $(18 \%), \beta$ blockers + ACE inhibitor+ ASA is used in 1 patients (2\%), ACE inhibitor+ Heparin+ ASA is used in 10 patients $(20 \%)$. ' $p$ ' value found significant. Here in this study results shows that 34 (64\%) MI patients are devoid of any complication, in this study commonly observed complications are, bleeding from cannula site is observed in 3 patients $(6 \%)$, mild gum bleeding 3 patients $(6 \%)$. ' $\mathrm{p}$ ' value found significant. The study results showed that 34 (64\%) MI patients are devoid of any complication, in this study commonly observed complications are, bleeding from cannula site is observed in 3 patients $(6 \%)$, significant mild gum bleeding for 3 patients $(6 \%)$.
After appropriate use of streptokinase patient physical condition at discharge were observed, 44\% patients got better outcome, were as $30 \%$ got Improved outcome, $16 \%$ patient referred for further higher treatment, since AMI is very close to higher risk of mortality $10 \%$ patients were expired during the time of treatment.

Table-1: Demographic characteristics of patients

\begin{tabular}{|l|l|l|}
\hline S. No & Gender & No of patients(n) \\
\hline 1 & Male & $27(54 \%)$ \\
\hline 2 & Female & $23(46 \%)$ \\
\hline Median & 25 \\
\hline Mean & 25 \\
\hline SD & 2.825 \\
\hline 'P' Value & $\begin{array}{l}<0.0500 \\
\text { Significant }\end{array}$ \\
&
\end{tabular}

Table-2: Age \& Gender wise distribution

\begin{tabular}{|l|l|l|l|l|}
\hline \multirow{2}{*}{ S. No } & \multirow{2}{*}{ Age } & \multicolumn{2}{|l|}{ No of patients(n) } & \multirow{2}{*}{ Total } \\
\cline { 3 - 4 } & & Male & Female & \\
\hline 1 & $50-60$ & 7 & 8 & 15 \\
\hline 2 & $60-70$ & 16 & 13 & 29 \\
\hline 3 & Above 70 & 4 & 2 & 06 \\
\hline MEDIAN & 7 & 8 & \\
\cline { 1 - 3 } MEAN & 9 & 7.7 & \\
\hline S.D & 3.606 & 3.180 & \\
\hline 'p' value & $\begin{array}{l}0.1299 \\
\text { Non-significant }\end{array}$ \\
\hline
\end{tabular}

Table-3: Co-morbid conditions of patients

\begin{tabular}{|l|l|l|l|}
\hline \multirow{2}{*}{ S. No } & \multirow{2}{*}{ Co-morbidities } & \multicolumn{2}{|l|}{ No of Patients(n) } \\
\cline { 3 - 4 } & & yes & No \\
\hline 1 & Diabetes mellitus(DM) & 23 & 27 \\
\hline 2 & Hyper tension(HTN) & 41 & 9 \\
\hline 3 & Ischemic heart disease (IHD) & 7 & 43 \\
\hline 4 & Dyslipidaemia & 33 & 17 \\
\hline 5 & Stroke & 9 & 41 \\
\hline 6 & Kidney disease & 10 & 40 \\
\hline MEDIAN & 16.50 & 33.50 \\
\hline MEAN & 20.50 & 29.50 \\
\hline SD & 14.20 & 14.20 \\
\hline 'p' VALUE & O.O166 \\
\hline
\end{tabular}

Table-4: Co-morbidities at the time of admission

\begin{tabular}{|l|l|l|}
\hline S .No & Co-morbidities at present & Number of patients(n) \\
\hline 1 & Hypotension & 2 \\
\hline 2 & Hypotension + 2nd degree AV block & 1 \\
\hline 3 & Hypotension + cardiogenic shock & 1 \\
\hline 4 & IWMI+2nd degree AV block & 1 \\
\hline 5 & Cardiac failure & 1 \\
\hline 6 & IWMI+ Cardiac failure & 1 \\
\hline 7 & L.V dysfunction & 4 \\
\hline 8 & Complete heart block & 1 \\
\hline 9 & RVMI + 2nd degree heart block & 1 \\
\hline 10 & Ventricular tachycardia & 2 \\
\hline 11 & 1st degree heart block & 1 \\
\hline
\end{tabular}


Mohamed Shameem et al.; Saudi J Med, Apr, 2021; 6(4): 65-69

\begin{tabular}{|l|l|l|}
\hline S .No & Co-morbidities at present & Number of patients(n) \\
\hline 12 & RBBB & 1 \\
\hline 13 & NILL & 30 \\
\hline Median & 1 \\
\hline Mean & 3.615 \\
\hline SD & 7.974 \\
\hline 'p' value & $>0.1285$ \\
& Non-significant \\
\hline
\end{tabular}

Table-5: ECG findings in MI patients

\begin{tabular}{|l|l|l|}
\hline S. No & Site of infarction & Number of patients(n) \\
\hline 1 & IWMI & 26 \\
\hline 2 & AWMI & 23 \\
\hline 3 & LWMI & 1 \\
\hline 4 & RVMI & 2 \\
\hline 5 & 2nd degree A.V block & 1 \\
\hline 6 & Complete heart block & 1 \\
\hline 7 & RVMI +2nd degree heart block & 1 \\
\hline Median & 1 \\
\hline Mean & 7.87 \\
\hline SD & 11.41 \\
\hline 'p' value & $<0.0156$ \\
\end{tabular}

Table-6: Combination therapy used in MI

\begin{tabular}{|l|l|l|l|}
\hline S. No & Drugs & Number of patients(n) & $\%$ \\
\hline 1 & $\beta$ blockers +ACE inhibitor+ Heparin+ ASA & 26 & 52 \\
\hline 2 & $\beta$ blockers + Heparin+ ASA & 9 & 18 \\
\hline 3 & $\beta$ blockers +ACE inhibitor+ ASA & 1 & 2 \\
\hline 4 & ACE inhibitor+ Heparin+ ASA & 10 & 20 \\
\hline 5 & Heparin+ ASA & 2 & 4 \\
\hline 6 & $\beta$ blockers + ASA & 1 & 2 \\
\hline 7 & ASA & 1 & 2 \\
\hline Median & 2 & \\
\hline Mean & 7.143 & \\
\hline SD & 9.191 & \\
\hline 'p' value & 0.0093 \\
\end{tabular}

Table-7: Post thrombolytic complication

\begin{tabular}{|l|l|l|}
\hline S. No & Post thrombolytic complication & Number of patients(n) \\
\hline 1 & Bleeding from cannula site & 3 \\
\hline 2 & Shock & 1 \\
\hline 3 & Mild internal bleeding & 2 \\
\hline 4 & Mild gum bleeding & 3 \\
\hline 5 & Intra cranial bleeding & 1 \\
\hline 6 & Cardiac failure & 3 \\
\hline 7 & Complete heart block & 1 \\
\hline 8 & Gastro intestinal bleeding & 1 \\
\hline 9 & Ventricular Tachycardia & 1 \\
\hline 10 & NILL & 34 \\
\hline Median & & 1 \\
\hline Mean & 1.778 \\
\hline SD & 0.9718 \\
\hline 'p' value & 0.0020 \\
& significant \\
\hline
\end{tabular}


Mohamed Shameem et al.; Saudi J Med, Apr, 2021; 6(4): 65-69

Table-8: Physical condition at discharge

\begin{tabular}{|l|l|l|l|}
\hline $\begin{array}{l}\text { S. } \\
\text { No }\end{array}$ & $\begin{array}{l}\text { Physical } \\
\text { condition }\end{array}$ & $\begin{array}{l}\text { Number of } \\
\text { patients(n) }\end{array}$ & \% \\
\hline 1 & Better & 22 & 44 \\
\hline 2 & Improved & 15 & 30 \\
\hline 3 & Referred & 8 & 16 \\
\hline 4 & Expired & 5 & 10 \\
\hline \multicolumn{2}{|l|}{ Median } & 11.50 & 23 \\
\hline \multicolumn{2}{|l|}{ Sean } & 12.5 & 25 \\
\hline SD & 7.594 & \\
\hline 'p' value & $\begin{array}{l}0.0460 \\
\text { Significant }\end{array}$ \\
\hline
\end{tabular}

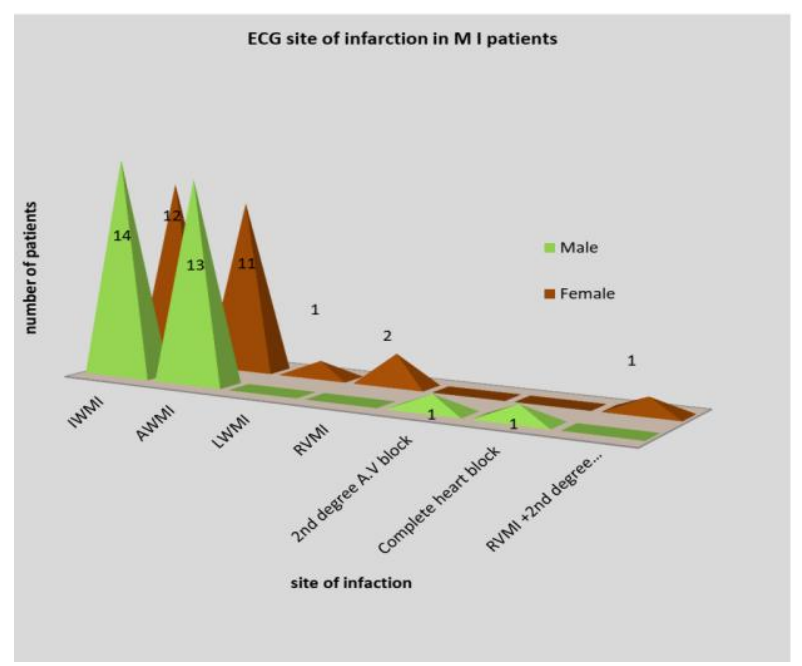

Fig-1: ECG site of infarction

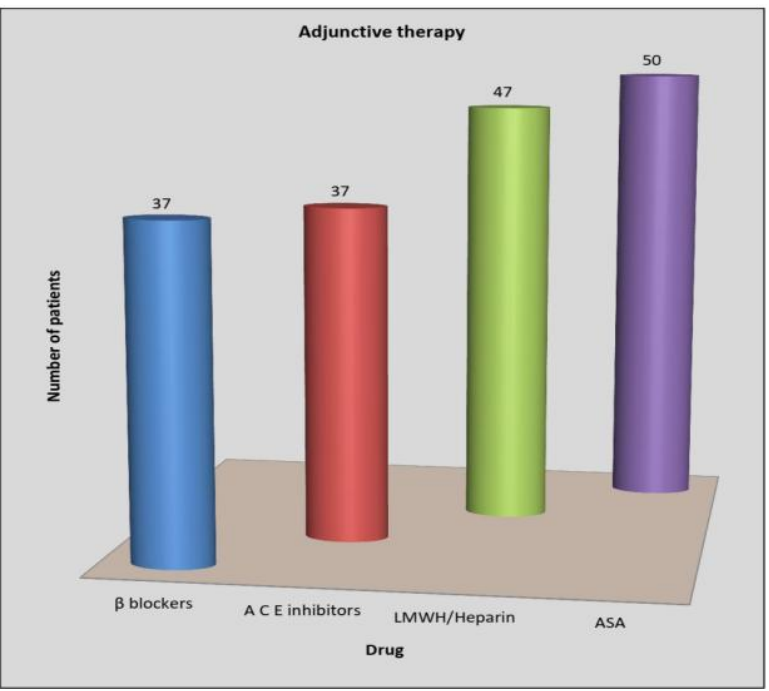

Fig-2: Adjuvant therapy in MI patients

\section{CONCLUSION}

The study showed that mortality rate due to MI is increased. So the use of cost effective and well established thrombolytic drugs is necessary. Streptokinase was used as a drug of first choice for those patients admitted in CCU of Saba hospital after the onset of symptoms
Maximum of no of patients have better $(44 \%)$ physical condition relative to improved (30\%) conditions. Whereas few cases referred (16\%) for further treatment and $10 \%$ patients got expired within the period of time. In conclusion strict follow up is required for when patient treated by streptokinase drug for better patient outcome.

\section{ACKNOWLEDGEMENT}

All the authors thanks to Saba Hospital, Pyannur, Kerala to provide facilities to carry out the study.

\section{REFERENCES}

1. Gilbert, J. A., \& Clancy, M. (2003). Patient knowledge of thrombolysis in acute myocardial infarction. Emergency medicine journal, 20(1), 5253.

2. GISSI Study Group. (1986). Effectiveness of intravenous thrombolytic treatment in acute myocardial infarction. Lancet, 22, 397-401.

3. Zoltie, N., \& Robertson, G. (1995). Changing Standard for Thrombolytic in accident and emergency departments. Journal of Accident and Emergency Medicine, 1(3), 132-133.

4. Golino, P., \& Willerson, J. T. (1991). Is Thrombolysis Alone the Best Therapy for Acute Myocardial Infarction?: Current Status and Emerging Strategies. Texas Heart Institute Journal, 18(1), 50.

5. Murray, N. E. I. L., Lyons, J. O. H. N., Layton, C. L. I. V. E., \& Balcon, R. A. P. H. A. E. L. (1987). What proportion of patients with myocardial infarction are suitable for thrombolysis?. Heart, 57(2), 144-147.

6. Cantor, W. J., Fitchett, D., Borgundvaag, B., Ducas, J., Heffernan, M., Cohen, E. A., ... \& Goodman, S. G. (2009). Routine early angioplasty after fibrinolysis for acute myocardial infarction. New England Journal of Medicine, 360(26), 2705-2718.

7. Meier, M. A., Al-Badr, W. H., Cooper, J. V., Kline-Rogers, E. M., Smith, D. E., Eagle, K. A., \& Mehta, R. H. (2002). The new definition of myocardial infarction: diagnostic and prognostic implications in patients with acute coronary syndromes. Archives of internal medicine, 162(14), 1585-1589.

8. Nee, P. A. (1997). Thrombolysis after acute myocardial infarction. Emergency Medicine Journal, 14(1), 2-9.

9. Tough, J., \& Berry, L. (2005). Thrombolytic therapy in acute myocardial infarction. Nursing Standard (through 2013), 19(37), 55-64.

10. Wilmshurst, P., Purchase, A., Webb, C., Jowett, C., \& Quinn, T. (2000). Improving door to needle times with nurse initiated thrombolysis. Heart, 84(3), 262-266. 